\title{
The top 100 cited articles in urology: An update
}

\author{
Gregory J. Nason, MD, MRCSl; ${ }^{\dagger}$ Farhan Tareen, MD; ${ }^{\dagger}$ Alan Mortell, MD
}

*Department of Pediatric Surgery and Urology, Our Lady's Children's Hospital, Crumlin, Dublin, Ireland; 'Surgical Registrar, Our Lady's Children's Hospital, Crumlin, Dublin, Ireland; §Consultant Pediatric Surgeon, Our Lady's Children's Hospital, Crumlin, Dublin, Ireland

Cite as: Can Urol Assoc J 2013;7(1):E16-E24. http://dx.doi.org/10.5489/cuaj.12223

\section{Abstract}

Background: In this paper, we identify and analyze the top 100 cited articles in urology since 1965 and assess changes in the top 100 since 2007.

Methods: We selected highest impact journals in both urological and general medicine journals from the 2011 edition of Journal Citation Reports: Science edition. We identified and analyzed the 100 most cited articles using the Science Citation Index Expanded (1965-present).

Results: The top 100 articles were cited a mean of 892 times (range: 529-2088) and published between 1966 and 2009, with 21 published since 2000. In 2012, 19 new articles appeared in the updated top 100 cited articles. Also, 16 journals were represented, led by the New England Journal of Medicine $(n=36)$, the Journal of Urology $(n=16)$ and the Lancet $(n=12)$. In total, 81 articles were published from North America (USA $=77$, Canada=4). From the United States, the following institutes were among the top 5 represented: Johns Hopkins University $(n=12)$, Harvard University, Memorial Sloan Kettering Cancer Centre, National Institute of Health and Washington University (all 5). Only one institute outside the United States published more than one article in the top 100 (Institut Gustave Roussy, France). Nine urologists were first authors of 2 or more articles. Oncology $(n=54)$ and transplantation $(n=22)$ were the most common subspecialties represented.

Conclusion: It is important to acknowledge the top cited articles as they mark key topics and advances in urology. There has been a $19 \%$ change in the top 100 cited articles in the past 5 years. Oncology and transplantation remain the most highly cited topics.

\section{Introduction}

There are an ever increasing number of medical and specialty journals publishing articles at a prolific rate, but to a varying degree of quality. ${ }^{1}$ Urology is a highly competitive surgical subspecialty and some trainees may be tempted to improve their curriculum vitae without adhering to the rigors of academic probity. ${ }^{2}$ Almost 1 in every 6 original articles published in leading surgical journals include some form of redundancy. ${ }^{3}$ A redundant publication is one which duplicates previous, simultaneous or future publications by the same author or group or, alternatively, could have been combined with the latter into one paper.

The establishment of a citation rank list has been often used in medicine to identify works that have had the greatest intellectual influence. ${ }^{4}$ When a peer-reviewed article references another publication, a "citation" is received. Citation analysis involves ranking and evaluating an article or journal based on the number of citations it receives. In addition to determining the most frequently cited articles, this analysis is also used to rank journals in terms of impact. Multiple medical fields have used a rank list to determine the impact of articles and journals within its specialty, such as otolaryngology, ${ }^{5}$ general surgery, ${ }^{6}$ plastic surgery, ${ }^{7}$ urology, $^{8}$ orthopaedics $^{9}$ and pediatric orthopaedics. ${ }^{10}$ Although the significance of citation analysis remains controversial, proponents point out that this method provides the only objective method to determine the significance of an article or journal. ${ }^{11,12}$

Hennessey and colleagues published "the top 100 cited articles in urology" reviewing articles up to $2007 .{ }^{13}$ A list of the most influential papers was compiled and their characteristics assessed for authorship and content. The paper identified topics and authors that contributed to major advances in urology. In this study, we identify and update the 100 most frequently cited articles published in urology and determine if there have been changes since 2007.

\section{Methods}

To identify the most frequently cited articles published in urology, we selected 90 of the highest impact journals dedicated to urology and its subspecialty areas (Transplantation, Nephrology, Infectious Diseases and Sexual Health), as well as 32 of the highest impact general medical and medical research journals from the 2011 edition of Journal Citation Reports (JCR): Science Edition. 
Table 1. The top 100 cited articles in urology, 2007 and 2012

Ranking

2012 (2007)

Article

\begin{tabular}{cc}
$\begin{array}{c}\text { No. } \\
\text { citations } \\
\text { (2012) }\end{array}$ & $\begin{array}{c}\text { No. } \\
\text { citations } \\
\text { (2007) }\end{array}$ \\
\hline 2088 & 1435 \\
2030 & 716 \\
1792 & \\
1742 & \\
1723 & \\
1694 & 957 \\
1688 & 901
\end{tabular}

1529

1525

1122

Palermo G, et al. Pregnancies after intracytoplasmic injection of single spermatozoon into an oocyte. Lancet 1992;340:17-8.

$10(2)$ Stamey TA, et al. Prostate-sper

$11(58)$

Yang JC, et al. A randomized trial of bevacizumab, an anti-vascular endothelial growth factor antibody, for metastatic renal cancer. N Engl J Med 2003;349:427-34.

Barry MJ, et al. The American Urological Association symptom index for benign prostatic hyperplasia. The Measurement Committee of the American Urological Association. J Urol 1992;148:1549-57.

$13(24)$ Pound CR, et al. Natural history of progression after PSA elevation following radical prostatectomy. JAMA 1999;281:1591-7.

$14(45) \quad$ Wolfe RA, et al. Comparison of mortality in all patients on dialysis, patients on dialysis awaiting transplantation and recipients of a first cadaveric transplant. N Engl J Med 1999;341:1725-30. Catalona WJ, et al. Measurement of prostate-specific antigen in serum as a screening test for prostate cancer. N Engl J Med 1991;324:1156-61.

$16(12)$

Chan JM, et al. Plasma insulin-like growth factor-I and prostate cancer risk: a prospective study. Science 1998;279:563-6.

17 (3) Einhorn LH, et al. Cis-diamminedichloroplatinum, vinblastine, and bleomycin combination chemotherapy in disseminated testicular cancer. Ann Intern Med 1977;87:293-8.

18 (59) Rayman MP. The importance of selenium to human health. Lancet 2000;356:233-41.

Petrylak DP, et al. Docetaxel and estramustine compared with mitoxantrone and prednisone for advanced refractory prostate cancer. N Engl J Med 2004;351:1513-20.

$19(*)$

Goldstein I, et al. Oral sildenafil in the treatment of erectile dysfunction. Sildenafil Study Group. N Engl 20 (6) J Med 1998;338:1397-404

Carlsen E, et al. Evidence for decreasing quality of semen during past 50 years. BMJ 1992;305:609-13. Gleason DF, et al. Prediction of prognosis for prostatic adenocarcinoma by combined histological grading and clinical staging. J Urol 1974;111:58-64.

Sharpe RM, et al. Are oestrogens involved in falling sperm counts and disorders of the male reproductive tract? Lancet 1993;341:1392-5.

D'Amico AV, et al. Biochemical outcome after radical prostatectomy, external beam radiation therapy, or interstitial radiation therapy for clinically localized prostate cancer. JAMA 1998;280:969-74.

Partin AW, et al. Combination of prostate-specific antigen, clinical stage, and Gleason score to predict pathological stage of localized prostate cancer. A multi-institutional update. JAMA 1997;277:1445-51.

$26(*) \quad$ Thompson IM, et al. The influence of finasteride on the development of prostate cancer. N Engl J Med
Droller MJ, et al. Impotence. JAMA 1993;270:83-90.

Crawford ED, et al. A controlled trial of leuprolide with and without flutamide in prostatic carcinoma. $\mathrm{N}$ Engl J Med 1989;321:419-24.
1491

1488

516

1397

942

1348

774

1312

584

1304

1052

1303

901

1277

1209

1268

514

1253

1238

973

1225

849

1208

924

1193

910

1112

418

1107

755

1093

1086

761

1022

870 
Table 1. The top 100 cited articles in urology, 2007 and 2012 (cont'd)

\section{Ranking}

2012 (2007)

29 (18) Robson CJ, et al. The results of radical nephrectomy for renal cell carcinoma. J Urol 1969;101:297-301.

30 (28)

31 (33)

32(13)

35 (19)

$36(20)$

37 (32)

$38(23)$

39 (16)

40 (26)

41 (21)

42 (35)

43 (36)

$44(51)$

45 (54)

$46\left(^{*}\right)$

47 (72)

$48(*)$

49 (37)

$50(70)$

51(29)

52 (42)

\section{Article}

Berry SJ, et al. The development of human benign prostatic hyperplasia with age. J Urol 1984;132:4749.

Hariharan S, et al. Improved graft survival after renal transplantation in the United States, 1988 to 1996. N Engl J Med 2000;342:605-12.

Oesterling JE. Prostate specific antigen: a critical assessment of the most useful tumor marker for adenocarcinoma of the prostate. J Urol 1991;145:907-23.

Solez K, et al. International standardization of criteria for the histologic diagnosis of renal allograft rejection: the Banff working classification of kidney transplant pathology. Kidney Int 1993;44:411-22.

Sollinger HW. Mycophenolate mofetil for the prevention of acute rejection in primary cadaveric renal allograft recipients. U.S. Renal Transplant Mycophenolate Mofetil Study Group. Transplantation 1995;60:225-32.

Opelz G, et al. Effect of blood transfusions on subsequent kidney transplants. Transplant Proc 1973;5:253-9.

Loehrer PJ, et al. Drugs 5 years on: Cisplatin. Ann Intern Med 1984;100:704-13.

Bolla $\mathrm{M}$, et al. Improved survival in patients with locally advanced prostate cancer treated with radiotherapy and goserelin. N Engl J Med 1997;337:295-300.

Mebust WK, et al. Transurethral prostatectomy: immediate and postoperative complications. A cooperative study of 13 participating institutions evaluating 3,885 patients. J Urol 1989;141:243-7.

Calne RY, et al. Cyclosporin A in patients receiving renal allografts from cadaver donors. Lancet 1978;2:1323-7.

Belzer FO, et al. Principles of solid organ preservation by cold storage. Transplantation 1988;45:673-6.

Gabrilove JL, et al. Effect of granulocyte colony-stimulating factor on neutropenia and associated morbidity due to chemotherapy for transitional-cell carcinoma of the urothelium. N Engl J Med 1988;318:1414-22.

Oesterling JE, et al. Serum prostate-specific antigen in a community-based population of healthy men. Establishment of age-specific reference ranges. JAMA 1993;270:860-4.

Catalona WJ, et al. Comparison of digital rectal examination and serum prostate specific antigen in the early detection of prostate cancer: results of a multicenter clinical trial of $6,630 \mathrm{men}$. J Urol 1994;151:1283-90.

Walsh PC, et al. Impotence following radical prostatectomy: insight into etiology and prevention. J Urol 1982;128:492-7.

Clayman RV, et al. Laparoscopic nephrectomy: initial case report. J Urol 1991;146:278-82.

Gardner SD, et al. New human papovavirus (B.K.) isolated from urine after renal transplantation. Lancet 1971;1:1253-7.

Motzer RJ, et al. Renal-cell carcinoma. N Engl J Med 1996;335:865-75.

Thompson IM, et al. Prevalence of prostate cancer among men with a prostate-specific antigen level $<$ or $=4.0$ ng per milliliter. N Engl J Med 2004;350:2239-46.

Williams SD, et al. Treatment of disseminated germ-cell tumors with cisplatin, bleomycin, and either vinblastine or etoposide. N Engl J Med 1987;316:1435-40.

Epstein Jl, et al. Pathologic and clinical findings to predict tumor extent of nonpalpable (stage T1c) prostate cancer. JAMA 1994;271:368-74.

*New articles, not included in the top 100 in 2007.

The impact factor of a journal is calculated based on a 2-year period. It is the mean number of citations in a year given to those papers in a journal that were published during the 2 preceding years. We found 90 urology and subspecialty journals under the subject categories "Urology and Nephrology" and "Transplantation" in the JCR 2011. We included all journals except 3 nephrology journals and 2 transplant journals, as they did not pertain to urology. We selected 32 general medical and medical research journals by searching the JCR 2011 subject categories 
Table 1. The top 100 cited articles in urology, 2007 and 2012 (cont'd)

\section{Ranking}

$2012(2007)$

Article $\begin{array}{cc}\text { No. } & \text { No. } \\ \text { citations } & \text { citations }\end{array}$

(2012)

(2007)

Grinyo JM. Placebo-controlled study of mycophenolate mofetil combined with cyclosporin and

53 (39) corticosteroids for prevention of acute rejection. European Mycophenolate Mofetil Cooperative Study Group. Lancet 1995;345:1321-5.

54 (31)

Sidransky D, et al. Identification of p53 gene mutations in bladder cancers and urine samples. Science 1991;252:706-9.

749

619

747

709

Andriole GL, et al. Mortality results from a randomized prostate-cancer screening trial. N Engl J Med

$551^{*}$ 2009;360:1310-9.

$56(*) \quad H a r i s i n g h a n i$ MG, et al. Noninvasive detection of clinically occult lymph-node metastases in prostate cancer. N Engl J Med 2003;348:2491-9.

746

741

Carter HB, et al. Longitudinal evaluation of prostate-specific antigen levels in men with and without prostate disease. JAMA 1992;267:2215-20.

Hodge KK, et al. Random systematic versus directed ultrasound guided transrectal core biopsies of the prostate. J Urol 1989;142:71-4.

$59(*) \quad$ Escudier B, et al. Bevacizumab plus interferon alfa-2a for treatment of metastatic renal cell carcinoma: a randomised, double-blind phase III trial. Lancet 2007;370:2103-11.

Gormley GJ, et al. The effect of finasteride in men with benign prostatic hyperplasia. The Finasteride Study Group. N Engl J Med 1992;327:1185-91.

Patel R, et al. Significance of the positive crossmatch test in kidney transplantation. N Engl J Med 1969;280:735-9.

$61(57)$

Pirsch JD, et al. A comparison of tacrolimus (FK506) and cyclosporine for immunosuppression after

62 (43) $\quad$ cadaveric renal transplantation. FK506 Kidney Transplant Study Group. Transplantation 1997;63:977-83. placebo-controlled phase III trial. Lancet 2008;372:449-56.

64 (34) Cohen DJ, et al. Cysclosporine: a new immunosuppressive agent for organ transplantation. Ann Intern Med 1984;101:667-82.

Catalona WJ, et al. Detection of organ-confined prostate cancer is increased through prostate-specific antigen-based screening. JAMA 1993;270:948-54.

$66(52)$

Morales A, et al. Intracavitary Bacillus Calmette-Guerin in the treatment of superficial bladder tumors. J Urol 1976;116:180-3.

$67(*) \quad$ Rosen RC, et al. Development and evaluation of an abridged, 5 -item version of the International Index of Erectile Function (IIEF-5) as a diagnostic tool for erectile dysfunction. Int J Impot Res 1999;11:319-26.

Messing EM, et al. Immediate hormonal therapy compared with observation after radical

68 (74) prostatectomy and pelvic lymphadenectomy in men with node-positive prostate cancer. N Engl J Med 1999;341:1781-8.

Keown P. A blinded, randomized clinical trial of mycophenolate mofetil for the prevention of

69 (49) acute rejection in cadaveric renal transplantation. The Tricontinental Mycophenolate Mofetil Renal

Transplantation Study Group. Transplantation 1996;61:1029-37.

70 (62) Childs $\mathrm{R}$, et al. Regression of metastatic renal-cell carcinoma after nonmyeloablative allogeneic peripheral-blood stem-cell transplantation. N Engl J Med 2000;343:750-8.

Bill-Axelson A, et al. Radical prostatectomy versus watchful waiting in early prostate cancer. N Engl J

$71(*)$ Med 2005;352:1977-84.

$72(50)$

Heney NM, et al. Superficial bladder cancer: progression and recurrence. J Urol 1983;130:1083-6.

73 (61)
738

738

729

726

719

711

707

696

663

695

579

693

557

692

691

460

683

574

682

503

678

670

562

666

504

*New articles, not included in the top 100 in 2007.

"Medicine, General and Internal" and "Medicine Research and Experimental." We then ranked the journals by their respective impact factors.

We cross-referenced this list with the list of journals searched in the textbook Classic Papers in Urology ${ }^{14}$ and the 2009 paper by Hennessey and colleagues entitled "The top 100 cited articles in urology."13 In total, we searched 122 journals (90 urological/subspecialty and 32 medical/ research).

We identified the 100 most frequently cited urological articles from the 132 journals using the database of the Science Citation Index expanded (1956-present). We 
Table 1. The top 100 cited articles in urology, 2007 and 2012 (cont'd)

\section{Ranking}

2012 (2007)

$74(48)$

75 (75)

76 (67)

$77(41)$

78 (79)

$79(56)$

80 (84)

$\left.81{ }^{*}\right)$

82 (44)

$83(*)$

$84(*)$

$85\left(^{*}\right)$

$86(95)$

87 (53)

$88(*)$

89 (64)

$90(80)$

91 (94)

92 (63)

93 (66)

94 (85)

95 (89)

96 (97)

97 (76)

98 (87)

99 (65)

100 (69)

\section{Article}

No.

citations

(2012)

No.

citations

(2007)

Chodak GW, et al. Results of conservative management of clinically localized prostate cancer. N Engl J Med 1994;330:242-8.

Terasaki Pl, et al. High survival rates of kidney transplants from spousal and living unrelated donors. $\mathrm{N}$ Engl J Med 1995;333:333-6.

Taplin ME, et al. Mutation of the androgen-receptor gene in metastatic androgen-independent prostate cancer. N Engl J Med 1995;332:1393-8.

Cosimi $A B$, et al. Use of monoclonal antibodies to T-cell subsets for immunologic monitoring and treatment in recipients of renal allografts. N Engl J Med 1981;305:308-14.

658

576

647

460

635

481

Auger $\mathrm{J}$, et al. Decline in semen quality among fertile men in Paris during the past 20 years. N Engl J Med 1995;332:281-5.

631

606

626

454

Rajfer J, et al. Nitric oxide as a mediator of relaxation of the corpus cavernosum in response to

nonadrenergic, noncholinergic neurotransmission. N Engl J Med 1992;326:90-4.

625

523

Carani C, et al. Effect of testosterone and estradiol in a man with aromatase deficiency. N Engl J Med 1997;337:91-5.

622

445

Kass EH. Bacteriuria and the diagnosis of infections of the urinary tract; with observations on the use of methionine as a urinary antiseptic. Arch Intern Med 1957;100:709-14.

618

612

587 mutated RB gene. Science 1990;247:712-5.

Milsom I, et al. How widespread are the symptoms of an overactive bladder and how are they managed? A population-based prevalence study. BJU Int 2001;87:760-6.

606

601

600

McConnell JD, et al. The long-term effect of doxazosin, finasteride, and combination therapy on the

clinical progression of benign prostatic hyperplasia. N Engl J Med 2003;349:2387-98.

Groth CG, et al. Sirolimus (rapamycin)-based therapy in human renal transplantation: similar efficacy and different toxicity compared with cyclosporine. Transplantation 1999;67:1036-42.

581

422

Cohen AJ, et al. Hereditary renal-cell carcinoma associated with a chromosomal translocation. $\mathrm{N}$ Engl J Med 1979;301:592-5.

Kahan BD. Efficacy of sirolimus compared with azathioprine for reduction of acute renal allograft rejection: a randomised multicentre study. Lancet 2000;356:194-202.

579

579

576

499

Dong JT, et al. KAI1, a metastasis suppressor gene for prostate cancer on human chromosome

11p11.2. Science 1995;268:884-6.

Walsh PC, et al. Radical prostatectomy with preservation of sexual function: anatomical and pathological considerations. Prostate 1983;4:473-85.

Almond PS, et al. Risk factors for chronic rejection in renal allograft recipients. Transplantation 1993;55:752-6

Cooner $\mathrm{WH}$, et al. Prostate cancer detection in a clinical urological practice by ultrasonography, digital rectal examination and prostate specific antigen. J Urol 1990;143:1146-52

Esrig D, et al. Accumulation of nuclear p53 and tumor progression in bladder cancer. N Engl J Med 1994;331:1259-64.

Chillón M, et al. Mutations in the cystic fibrosis gene in patients with congenital absence of the vas deferens. N Engl J Med 1995;332:1475-80.

Vincenti $F$, et al. Interleukin-2-receptor blockade with daclizumab to prevent acute rejection in renal transplantation. N Engl J Med 1998;338:161-5.

Smith JR, et al. Major susceptibility locus for prostate cancer on chromosome 1 suggested by a genome-wide search. Science 1996;274:1371-4.

561

453

556

422

552

502

551

487

548

442

546

431

540

420

536

459

533

436

1972; 107:458-61.

Neal DE, et al. Epidermal growth factor receptors in human bladder cancer: comparison of invasive and superficial tumors. Lancet 1985;1:366-8

529

498

Stamey TA, et al. Prostate specific antigen in the diagnosis and treatment of adenocarcinoma of the prostate. II. Radical prostatectomy treated patients. J Urol 1989;141:1076-83. 


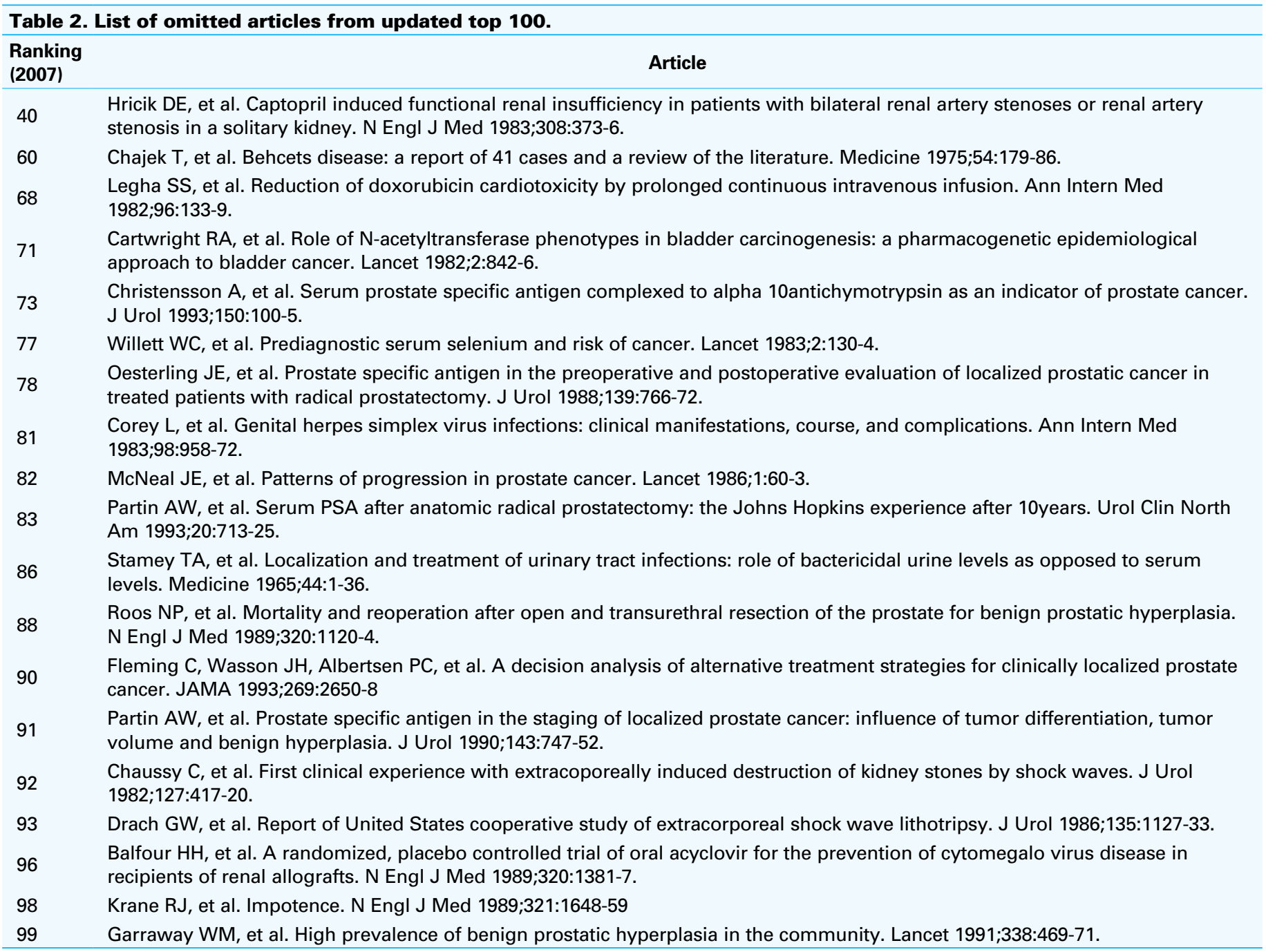

performed this search on October 5, 2012. This database includes publications from the 55-year period 1956 to 2011. We searched each of the 132 journals and included every article with greater than 100 citations in a comprehensive ranked list. The top 100 cited articles made up our final list (Table 1). We accessed and reviewed the articles online using MEDLINE. When relevant articles were not available online, we received articles in print format via the Royal College of Surgeons in Ireland library. We analyzed the articles and tabulated the data according to the number of citations, country and institute of origin, journal, impact factor, authorship and subspecialty.

\section{Results}

The mean number of citations for the top 100 articles was 892 (range: 529- 2088). The top 100 articles were published between 1957 and 2009 (Table 1). The oldest article was published in 1957 (Kass et al, Archives of Internal Medicine) and the most recent in 2009 (Andriole et al, New England Journal of Medicine). Of the 2007 top 100 list, 19 articles were not included in the 2012 update (Table 2).

The top 100 articles came from 10 countries, with $77 \%$ from the United States (Table 3). Sixteen institutions published 2 or more of the top 100 cited articles, with only 1 of these institutions from outside the United States (Institute Gustave Roussy, Villejuif, France). Nine investigators were first authors of 2 or more of the top 100 cited articles, originating from 8 institutions (Table 4).

Despite the fact that we searched 122 journals, the top 100 articles were published in $16(13.1 \%)$ journals: 7 urology, 7 general medicine and 2 transplantation journals (Table 5). Oncology (54) and transplantation (22) were the most commonly represented subspecialties (Table 6). Eighty-one articles were included in the top 100 cited articles published in 2009 . There was a $21 \%$ increase in the lowest number of 


\begin{tabular}{lc}
\hline $\begin{array}{l}\text { Table 3. Countries of origin of the top } \\
\text { urology }\end{array}$ & No. Articles \\
\hline Country & 77 \\
\hline United States of America & 6 \\
United Kingdom & 4 \\
France & 4 \\
Canada & 3 \\
Sweden & 2 \\
Spain & 1 \\
Denmark & 1 \\
Italy & 1 \\
Japan & 1 \\
Belgium & 1 \\
\hline
\end{tabular}

citations received to be included in the top 100 from 418 to 518 . One new country of origin (Japan) has been included with 2 falling out of the top 100 cited articles (Australia and Germany). Three of the top 5 institutions remain the same (Johns Hopkins University Hospital, Harvard University and Washington University).

\section{Discussion}

We have identified the top 100 articles in urology from 122 recognized peer-reviewed journals. Citation analysis was chosen as the determinant of selection. Although there is no direct correlation between citation frequency and study quality, it does offer an insight to the degree of peer analysis, the readership of the manuscript and a measure of recognition. A high citation frequency also demonstrates that other authors have formulated opinions on the topic and that it has generated discussion and debate. Citation analysis, although

\begin{tabular}{lcc}
\hline \multicolumn{3}{l}{$\begin{array}{l}\text { Table 4. Institutions of origin with 2 or more top-cited } \\
\text { articles in urology }\end{array}$} \\
\hline Rank & Institution & No. articles \\
\hline 1 & Johns Hopkins University & 12 \\
2 & Harvard University & 5 \\
3 & Memorial Sloan Kettering Cancer Centre & 5 \\
4 & Washington University & 5 \\
5 & National Institute of Health & 4 \\
6 & University of Texas & 4 \\
7 & Stanford University & 3 \\
8 & University of California, San Francisco & 3 \\
9 & University of California, Los Angeles & 3 \\
10 & Boston University & 2 \\
11 & Mayo Clinic & 2 \\
12 & University of Chicago & 2 \\
13 & University of Medicine and Dentistry of & 2 \\
14 & New Jersey & 2 \\
15 & University of Massachusetts & 2 \\
16 & University of Michigan & 2 \\
\hline
\end{tabular}

debatable, has been used widely as a standard of quality across medical specialities. ${ }^{5-10}$ Furthermore, these top 100 articles were published in 16 peer-reviewed journals of high quality demonstrated by their impact factor (mean 13.99, range: 1.005-53.298). The impact factor of a journal is generally accepted as a representation of the scientific quality of a publication. ${ }^{8}$

Publications and research have become key components in trainees' development. In many specialities, publications are one of the main discriminants between individuals. A list of the top 100 most cited articles demonstrates key papers

\begin{tabular}{lccc}
\hline \multicolumn{4}{l}{ Table 5. Journals in which the top $\mathbf{1 0 0}$ cited urological articles were published } \\
\hline Rank & Journal & No. articles & Impact factor (2011) \\
\hline 1 & New England Journal of Medicine & 36 & 53.298 \\
2 & Journal of Urology & 16 & 3.746 \\
3 & Lancet & 12 & 38.278 \\
4 & Journal of the American Medical Association & 11 & 30.026 \\
5 & Transplantation & 6 & 4.003 \\
6 & Science & 5 & 31.201 \\
7 & Annals of Internal Medicine & 3 & 16.733 \\
8 & British Medical Journal & 2 & 14.093 \\
9 & Kidney International & 2 & 6.606 \\
10 & Archives of Internal Medicine & 1 & 11.462 \\
11 & British Journal of Urology International & 1 & 2.844 \\
12 & International Journal Impotence Research & 1 & 1.712 \\
13 & Neurology and Urodynamics & 1 & 2.958 \\
14 & Prostate & 1 & 3.485 \\
15 & Transplantation Proceedings & 1 & 1.005 \\
16 & Urology & 1 & 2.428 \\
\hline
\end{tabular}




\begin{tabular}{lc}
\hline $\begin{array}{l}\text { Table 6. Most common subspecialties represented in the } \\
\text { top } \mathbf{1 0 0} \text { cited articles in urology }\end{array}$ \\
\hline Subspecialty & No. articles \\
\hline Oncology & 54 \\
Transplantation & 22 \\
Sexual function/infertility & 13 \\
Voiding dysfunction & 7 \\
Infection & 3 \\
Congenital abnormality & 1 \\
\hline
\end{tabular}

selected on citations in peer-reviewed journals. Although a flawed rank of quality, it does highlight an acceptance of their importance in the field. An awareness of these articles, mainly in high impact journals, can be an education to trainees regarding research methodology and ethical considerations.

There have been some changes to our updated list compared to the list published by Hennessey and colleagues in 2009. ${ }^{13}$ The topics of discussion have largely remained the same; oncology, transplantation and sexual function are the most common topics. There has been a $19 \%$ change in the composition of the top 100 articles, as well as a $21 \%$ increase in the number of citations necessary to enter the top 100. Most $(77 \%)$ high impact articles were published from the United States. In 2009, there were only 12 institutes that published more than 2 articles in the top 100 compared to 16 in our 2012 list. The top producing institute remained John Hopkins University. Only 1 institute from outside the United States produced more than 1 article in the top 100 list (Institut Gustave Roussy, France).

It is not possible to analyze the entire top 100 list; however, some interesting observations can be made from the top 10 articles. Three of the top 10 articles focus on sexual dysfunction (a topic that was included in the 2009 top 10). Ranked number 1, Feldman and colleagues discussed male impotence and its medical correlates. Ranked number 4, Laumann and colleagues discussed sexual dysfunction among men and women in the era of pharmacological advances in erectile dysfunction. While at number 7 , Rosen and colleagues discussed detecting treatment-related changes in men with erectile dysfunction. Two articles, ranked 3 (Motzer et al.) and 5 (Escudier et al.), discussed the changing chemotherapeutic agents available for the treatment of renal cell carcinoma demonstrating the advances in medical urooncology. These papers were published in the past decade, yet have received over 1400 citations, highlighting their importance and obvious effect on clinical practice.

Another paper marks the importance of medical oncology in the field of urology; ranked 8, the paper by Tannock and colleagues focused on the oncological management of prostate cancer. The remaining 4 articles in the top 10 include: at 10, Stamey and colleagues present a classic

\begin{tabular}{lc}
\hline $\begin{array}{l}\text { Table 7. Most common first authors of the top } \mathbf{1 0 0} \text { cited } \\
\text { articles in urology }\end{array}$ \\
\hline Author & No. articles \\
\hline Motzer RJ & 4 \\
Catalona WJ & 3 \\
Escudier B & 2 \\
Oesterling JE & 2 \\
Partin AW & 2 \\
Rosen RC & 2 \\
Stamey TA & 2 \\
Thompson IM & 2 \\
Walsh PC & 2
\end{tabular}

paper of prostate-specific antigen as a serum marker for prostate cancer; number 9, Palermo and colleagues discuss intracytoplasmic injection of spermatozoon; at number 6, Racusen and colleagues examine the Banff classification of renal allograft rejection; and at number 2, Abrams and colleagues review the standardization of terminology for lower urinary tract function (Table 7).

The limitations of this study are in the measure of a paper's quality. There is no unique way to assess the quality of an article. Citation analysis ignores the fact of a citation being positive or negative, as well as the phenomenon of selfcitation, which holds inherent bias. Furthermore, although not a unique research topic, it was prudent to highlight the dynamic process of a top 100 list. As time passes "landmark articles" are cemented in practice or disproved. New publications and developments in research and practice are forging their way into the top 100 . Without doubt, there is a time lag for promising papers to accumulate the number of citations to warrant inclusion in the top 100 . For this reason, we feel it necessary to update the top 100 most cited articles in urology on an ongoing basis (as is evident by the 19\% variation in the top 100 compilation).

\section{Conclusion}

This updated top 100 list highlights key papers in the field of urology. The top 100 articles were produced from some of the most reputable institutions across the world by world renowned urologists, clinicians and researchers. It is important for trainees to be aware of these key papers, which ultimately design the evidence-based clinical practice of urology.

Ranking the top 100 articles by their citation index underlines the attention these "classics" have received in the peer review process and the depth of discussion that has been created as a result of these studies. Knowledge of key papers is paramount to any surgical speciality and this update in urology highlights the changes in urological research. 
Nason et al.

Competing interests: None declared.

This paper has been peer-reviewed.

\section{References}

1. Hsi RS, Hotaling JM, Moore TN, et al. Publication misrepresentation among urology residency applicants. World J Urol 2012 Jun 23. [Epub ahead of print]. http://dx.doi.org/10.1007/s00345-012-0895-0

2. Fitzpatrick JM. Ethics in publishing. Can Urol Assoc J 2012;6:181-2. http://dx.doi.org/10.5489/ cuaj. 12126

3. Schein M, Paladugu R. Redundant surgical publications: tip of the iceberg? Surgery 2001;129:655-61. http://dx.doi.org/10.1067/msy.2001.114549

4. Murray MR, Wang T, Schroeder GD, et al. The 100 most cited spine articles. Eur Spine J 2012 Apr 17. [Epub ahead of print]. httrp://dx.doi.org/10.1007/s00586-012-2303-2

5. Fenton JE, Roy D, Hughes JP, et al. A century of citation classics in otolaryngology-head and neck Surgery journals. J Laryngol Otol 2002;1 16:494-8. http://dx.doi.org/10.1258/002221502760132557

6. Paladugu R, Schein $M$, Gardezi S, et al. One hundred citation classics in general surgical journals. World J Surg 2002;26:1099-105. http://dx.doi.org/10.1007/s00268-002-6376-7
7. Loonen MP, Hage JJ, Kon M. Plastic Surgery Classics: characteristics of 50 top-cited articles in four Plastic Surgery Journals since 1946. Plast Reconstr Surg 2008;121:320e-327e. http://dx.doi.org/10.1097/ PRS.0b013e31816bl3a9

8. Heldwein FL, Rhoden EL, Morgentaler A. Classics of urology: a half century history of the most frequently cited articles (1955-2009). Urology 2010;75:1261-8. http://dx.doi.org/10.1016/j.urology.2009.09.043

9. Kelly JC, Glynn RW, O'Briain DE, et al. The 100 classic papers of orthopaedic surgery: a bibliometric analysis. J Bone Joint Surg Br 2010;92:1338-43. http://dx.doi.org/10.1302/0301-620X.92B10.24867

10. Mehlman CT, Wenger DR. The top 25 at 25: citation classics in the Journal of Pediatric Orthopaedics. J Pediatr Orthop 2006;26:691-4. http://dx.doi.org/10.1097/01.bpo.0000235229.53163.de

11. Taubes G. Measure for measure in science. Science 1993;260:884-6. http://dx.doi.org/10.1126/ science. 8493516

12. Brody S. Impact factor as the best operational measure of medical journals. Lancet 1995;346:1300-1. $\mathrm{http}: / / \mathrm{dx}$.doi.org/10.1016/S0140-6736(95)91904-X

13. Hennessey K, Afshar K, MacNeily A. The top 100 cited articles in urology. Can Urol Assoc J 2009;3:293302.

14. Emberton M, Gerharz EW, O'Brien T. Classic Papers in Urology. Informa Healthcare: London, England; 1999

Correspondence: Mr, Gregory Nason, Department of Pediatric Surgery and Urology, Our Lady's Children's Hospital, Crumlin, Dublin 12, Ireland; fax: +35314096226; nasong@tcd.ie 